\title{
Intracapsular and Para-Articular Chondroma of the Infrapatellar Fat Pad of Hoffa: About A Case
}

M. Badraoui*, M. Ouali Idrissi, N. Idrissi Cherif El Ganouni

Radiology Department, University Hospital Center MOHAMED VI, Cadi Ayad University Marrakech, Morocco

DOI: $\underline{10.36347 / \text { sjmcr.2021.v09i01.010 }}$

| Received: 22.12.2020 | Accepted: 05.01.2021 | Published: 14.01.2021

*Corresponding author: M. Badraoui

Abstract

Case Report

The intracapsular chondroma of infra-patellar fat pad of Hoffa is a rare benign affection, manifested by anterior knee pain, resulting from the development of hyaline cartilage from the synovial membrane. A good knowledge of the radiological characteristics is the key to the diagnosis. We present a case of unilateral intracapsular and para-articular chondroma of the infrapatellar fat pad of Hoffa.

Keywords: Chondroma, infrapatellar fat pad of Hoffa.

Copyright $\left({ }^{\circ} 2021\right.$ The Author(s): This is an open-access article distributed under the terms of the Creative Commons Attribution 4.0 International License (CC BY-NC 4.0) which permits unrestricted use, distribution, and reproduction in any medium for non-commercial use provided the original author and source are credited.

\section{INTRODUCTION}

The intracapsular and para-articular chondroma of the infrapatellar fat pad of hoffa is a rare benign disease, characterized by the development of hyaline cartilage from the synovial membrane.

\section{ObServation}

36-year-old patient has progressive pain in the right knee associated with an enlarged lesion on the anterior side of the knee. The physical examination found a firm, mobile mass in the infrapatellar region. Standard radiography showed thickening of the medial soft tissue of the right knee. The osteo-articular ultrasound showed a lesion of Hoffa fat extended to the subcutaneous tissues opposite the patellar tendon, hypoechoic with individualization of the hyperechoic zones, discreetly vascularized with color doppler. MRI of the right knee revealed a well limited lesion in the infra-patellar fat of Hoffa extended in para articular, heterogeneous in $\mathrm{T} 1$ and $\mathrm{T} 2$ sequences with heterogeneous contrast enhancement after gadolinium injection, with individualization of fatty and fibrous zones, containing zones in hyposignal on all the sequences in connection with calcifications. An echoguided biopsy was carried out with an anatomopathological study which concluded that an intracapsular and para-articular chondroma of Hoffa fat pad was found. The patient underwent surgical resection.

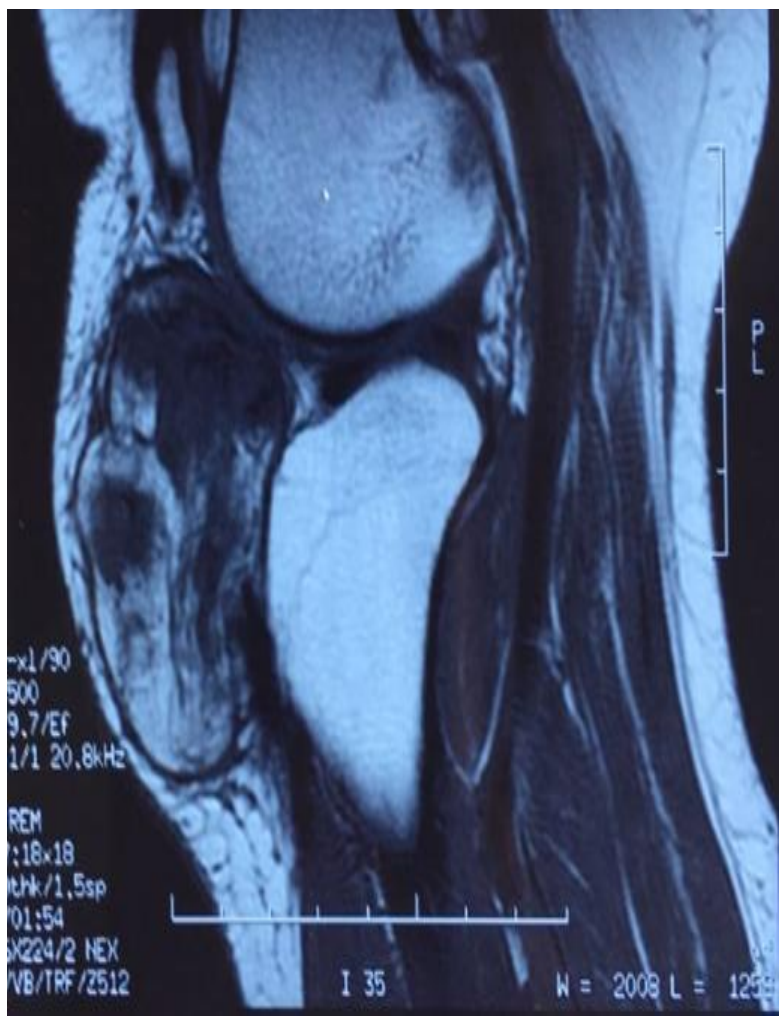

Fig-1: MRI of the right knee in sagittal T1 showing a lesion with clear contours, encapsulated, containing areas of hypointense signal and hyperintense signal 


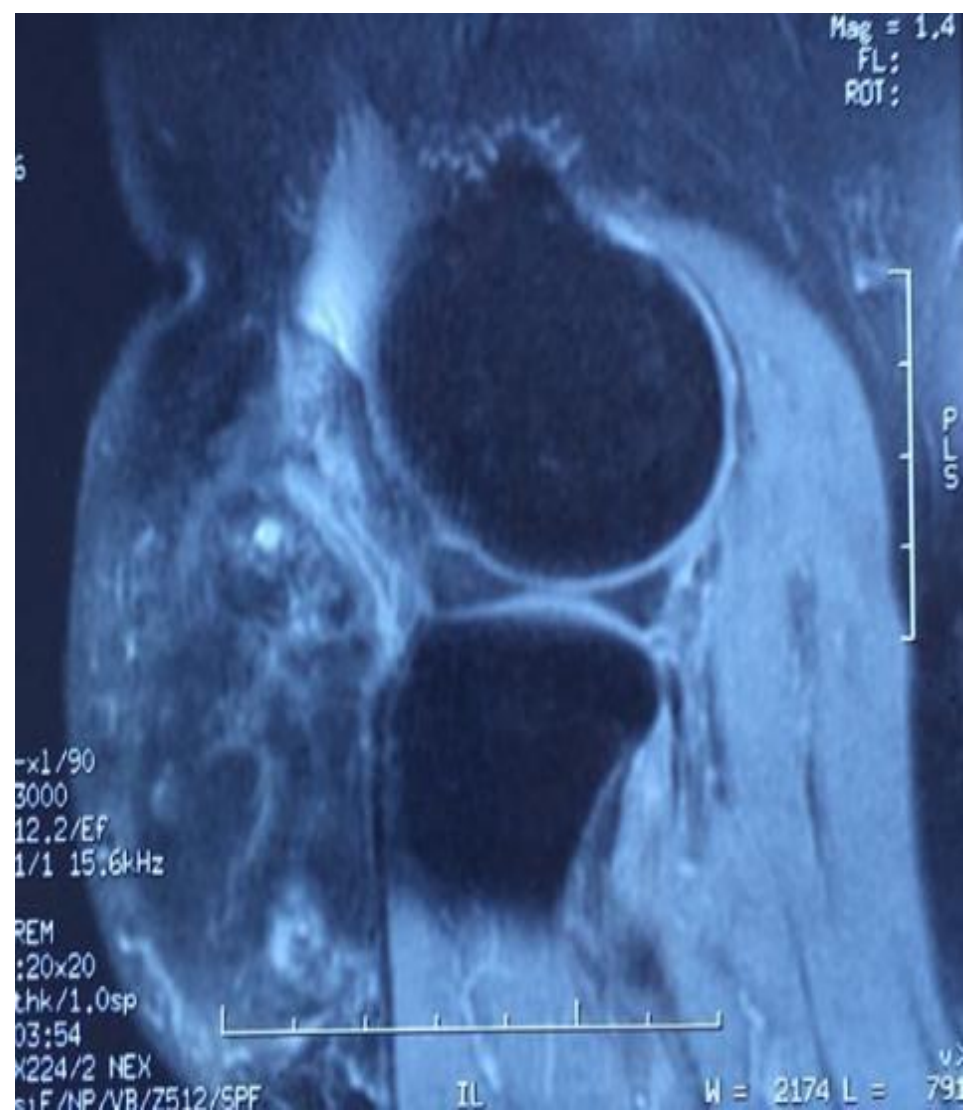

Fig-2: MRI of the right knee in sagittal T2 showing a lesion with clear contours, encapsulated, in heterogeneous signal T2

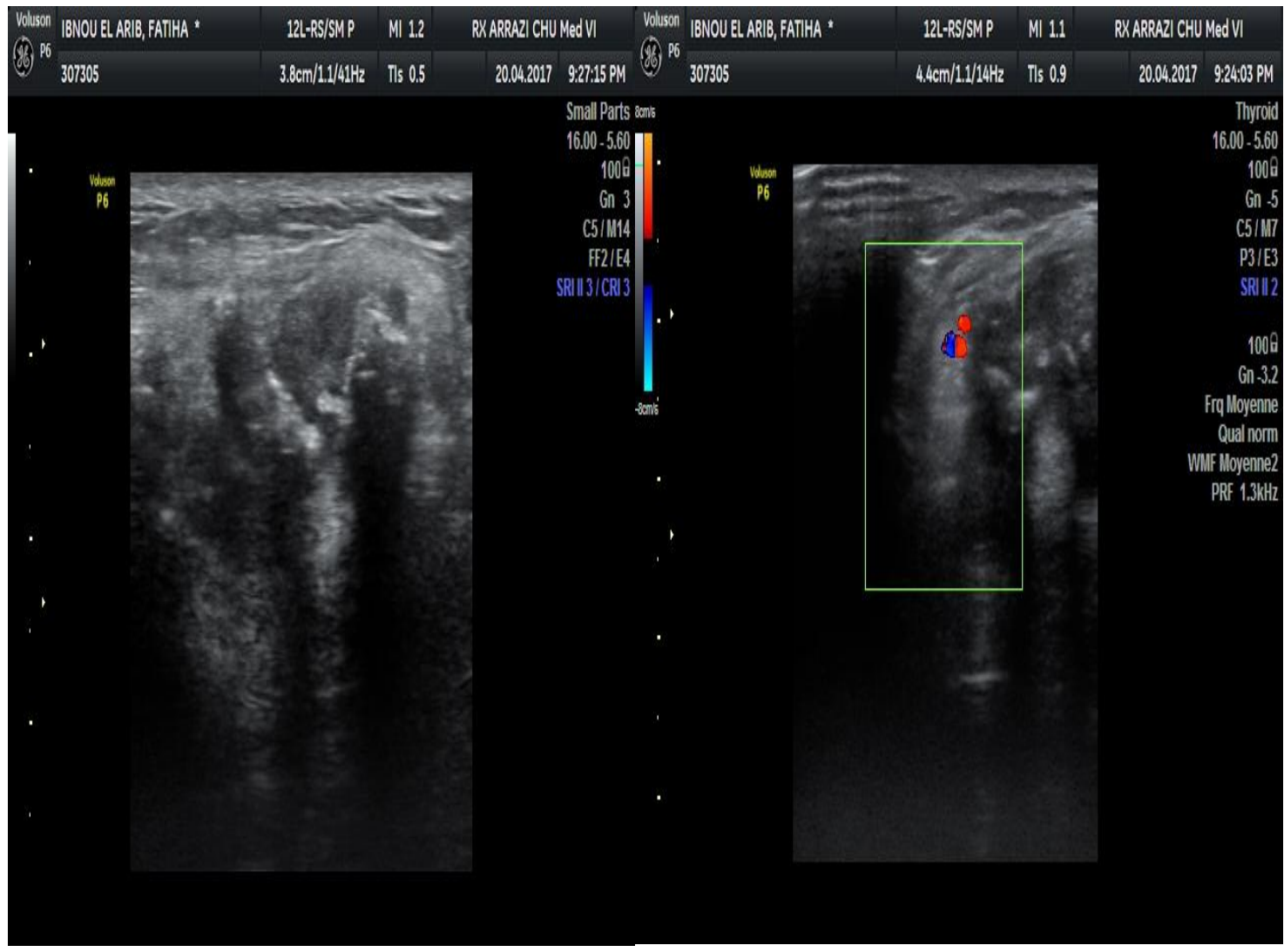

Fig-3: Ultrasound: showing a lesion of Hoffa's fat extended to the subcutaneous tissues opposite the patellar tendon, hypoechoic with individualization of hyperechoic areas, discreetly vascularized by color Doppler 

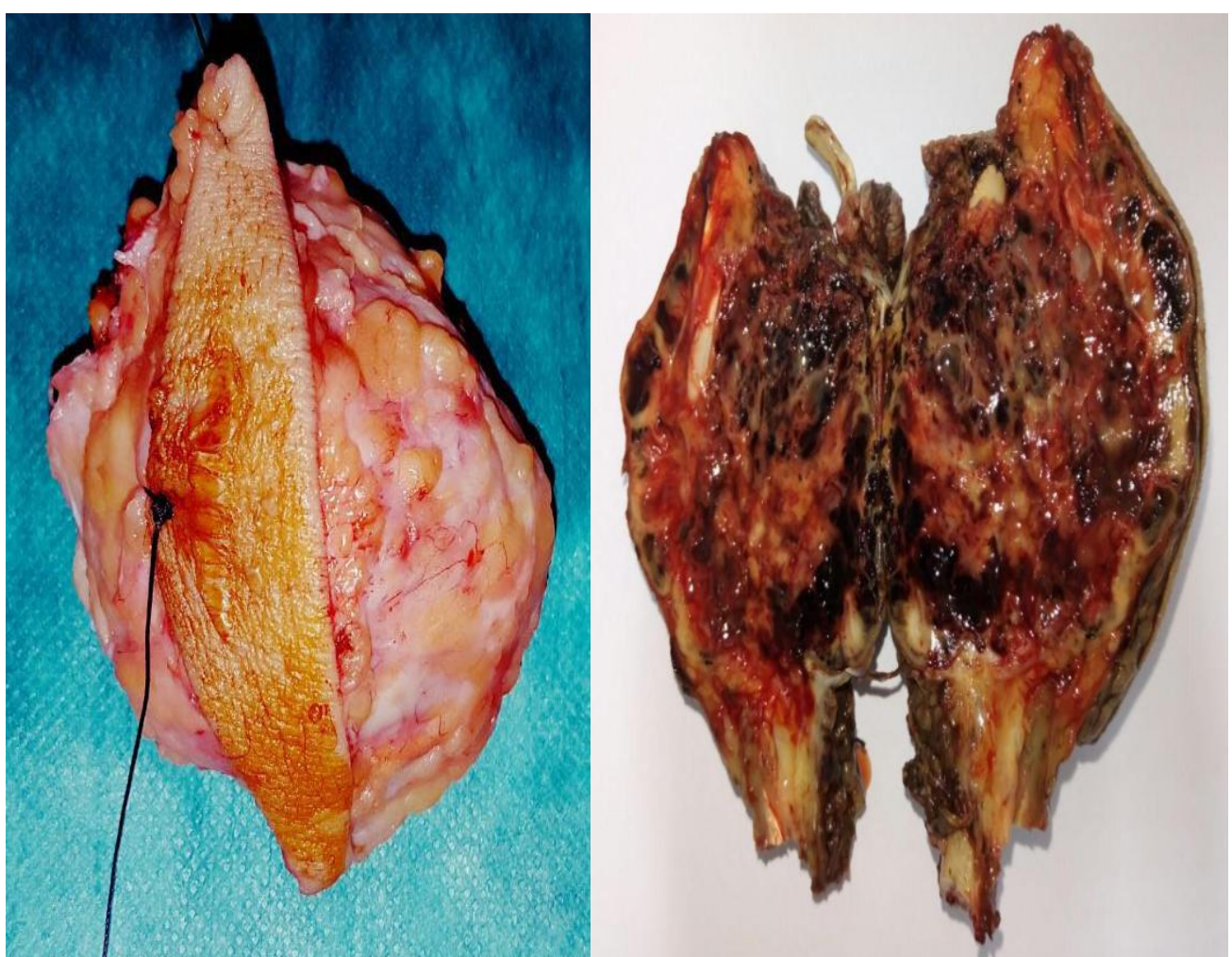

Fig-4: Macroscopic aspect of the operative part

\section{Discussion}

The intracapsular and para-articular chondroma of the infra-patellar fat pad of Hoffa is a benign, rare affection affecting the synovial joints. The underlying pathophysiology is considered to be a metaplastic change of the synovium to hyaline cartilage tissue. Its transformation to malignancy has been described but rare with an estimated risk of 5\% [1-3]. Correlation between standard X-ray and MRI data is essential to rule out differential diagnoses. Knowledge of this particular pathology is the key to diagnosis. It usually presents as a monoarthopathy. The knee joint is most often affected (43 to $68 \%$ of cases). The following sites with decreasing frequency are the hip, shoulder, elbow, ankle and wrist joints [3, 4]. Among patients with knee involvement, $10 \%$ have bilateral disease [2]. Symptoms that patients may complain of include pain, swelling of the affected limb and a palpable mass.

The standard x-ray are often normal [5]. MRI helps to better characterize lesions. Non-calcified and calcified lesions can be differentiated by MRI, in which non-mineralized chondromates are isointense signal in $\mathrm{T} 1$ but hyperintense signal in $\mathrm{T} 2$; whereas the mineralized lesions are hypointense signak on all the sequences [6].

The differential diagnosis includes Hoffa's disease, paraarticular osteochondroma and primary chondrosarcoma.

On histological examination, hypercellular lobules of hyaline cartilage from the synovium are found, nuclear atypia is common. It can be difficult to differentiate benign synovial chondromate from lowgrade chondrosarcoma, some features of malignancy include myxoid changes in cartilaginous cells in leaves rather than clusters and the presence of necrosis [1-3]. However, no definitive criteria for the diagnosis of malignancy exists. In our case, no defined malignant characteristic was detected.

The treatment of choice for intracapsular and para-articular chondroma is surgical excision. Malignant transformation has never been reported and local recurrence is rare [7-11]. Long-term follow-up is recommended due to the high frequency of recurrence and the risk of malignant transformation [12].

Due to the rarity of the disease, especially in association with an atypical presentation, the diagnosis is often not immediately apparent. However, it is generally suggested to carry out a radiological investigation, in particular an MRI, and then a confirmed histological analysis.

\section{CONCLUSION}

The intracapsular and para-articular chondromas of the infra-patellar fat of Hoffa are benign cartilaginous tumors which develop near the joints. The etiology of this lesion is not well known, but it probably results from repeated trauma which can be the cause of metaplasia of extra-synovial mesenchymal cells.

The intracapsular and para-articular chondroma of the infra-patellar fat of Hoffa is a rare 
M. Badraoui et al., Sch J Med Case Rep, Jan, 2021; 9(1): 39-42

affection of the synovial joints, a good knowledge of the radiological characteristics is the key to the diagnosis.

\section{REFERENCES}

1. Campanacci M. Bone and Soft Tissue Tumours, 2nd ed., Springer, New York, 1999.

2. Kransdorf M, Meis J. Extraskeletal osseous and cartilaginous tumours of theextremities, Radiographics. 1993; 13(4):853-884.

3. Davis RI, Hamilton A, Biggart JD. Primary synovial chondromatosis: aclinicopathological review and assessment of malignant potential, Hum Pathol. 1998; 29(7):683-688.

4. Milgram JW. Synovial osteochondromatosis. J Bone Joint Surg. 1977; 59A:792.

5. Christensen JH, Poulsen JO. Synovial chondromatosis, Acta Orthop Scand. 1975; 46:919.

6. Sheldon P, Forreste D, Learch T. Imaging of intraarticularmasses, Radiographics. 2005; 25(1):105-119.
7. Coolican MR, Dandy DJ. Arthoscopic management of synovialchondromatosis of the knee. Findings and results in 18 cases. J Bone Joint Surg. 1989; 71B:498.

8. Gilbert SR, Lacheiwicz PF. Primary synovial osteochondromatosis of the hip:report of two cases with long-term follow-up after synovectomy and a reviewof the literature. Am J Orthop. 1997; 26:555.

9. Ogilvie-Harris DJ, Saleh K. Generalised synovial chondromatosis of the knee: a comparison of removal of the loose bodies alone with arthoscopicsynovectomy, Arthroscopy. 1994; 10:166.

10. Shpitzer T, Ganel A, Engelberg S. Surgery for synovial chrondromatosis. 26cases followed up for 6 years, Acta Orthop Scand. 1990; 61:567.

11. Roulet E, Le Viet D. Primary synovial osteochondromatosis of the hand andwrist; report of a series of 21 cases and literature review. Rev Rheum Engl Ed. 1999; 66:256-266.

12. Bashaireh KM. Patellar subluxation with earlyphase synovialchondromatosis of the knee, Orthopedics. 2016; 39(1):176-179. 